\title{
Avaliação da produtividade de milho e controle de doenças foliares
}

Laís Teles de Souza ${ }^{1}$

José Luiz de Andrade Rezende Pereira²

Tamires Teles de Souza ${ }^{3}$

\section{Resumo}

Atualmente existem dezenas de doenças foliares que têm causado perdas significativas na cultura do milho. Entre elas, destacam-se a cercosporiose e a mancha branca. O presente trabalho teve, pois, como objetivo avaliar o efeito da aplicação de um fungicida, que possui como princípio ativo o mancozebe, na produtividade de híbridos de milho, e verificar a sua eficiência no controle das doenças foliares cercosporiose e mancha branca. O experimento foi conduzido no ano agrícola de 2011/2012, na fazenda experimental do IFSULDEMINAS - Campus Inconfidentes. Para a realização do trabalho foram utilizados híbridos selecionados de acordo com os níveis de resistência às doenças. 0 delineamento foi feito em blocos casualizados, com três repetições em esquema fatorial, no qual foram avaliados 8 (híbridos) x 3 aplicações do fungicida. Foram realizadas sete avaliações visuais da severidade das doenças a partir dos 90 dias após a emergência, por meio de escala de notas variando de 1 (altamente resistente) a 9 (altamente suscetível). Os grãos foram colhidos para a obtenção da produtividade dos híbridos, e a umidade foi ajustada para 13\%. A aplicação do fungicida foi eficiente no controle das doenças mancha branca e cercosporiose, no entanto, não aumentou a produtividade de grãos dos híbridos utilizados neste experimento. A aplicação do fungicida no estádio V6 e no pré-pendoamento das plantas de milho foi mais eficiente.

Palavras-chave: Cercospora zeae maydis. Phaeosphaeria maydis. Mancozebe. Severidade.

\section{Introdução}

A cultura do milho (Zea mays L.) apresenta uma ampla abrangência geográfica e grande importância econômica no mundo. No entanto, mesmo com a evolução gradativa das quantidades produzidas e rendimentos obtidos, a produção de grãos por unidade de área ainda não traduz o potencial genético das cultivares disponíveis, levando a constantes buscas por alternativas que aumentem a produtividade (GUARESCHI et al., 2008; TRENTO et al., 2002).

Por ser uma cultura que ocupa diversas condições edafoclimáticas, a cultura do milho possui um elevado número de doenças que já foram identificadas e que causam perdas significativas nas lavouras, sendo responsáveis pela dificuldade de exploração do máximo potencial genético de vários híbridos (POZAR et al., 2009).

\footnotetext{
1 Instituto Federal de Educação, Ciência e Tecnologia do Sul de Minas Gerais, discente do curso de graduação em Engenharia Agronômica. Inconfidentes, Minas Gerais, Brasil. laisteles.souza@hotmail.com. Rua JK, 79, centro, Inconfidentes, Minas Gerais, CEP 37.576-000.

2 Instituto Federal de Educação, Ciência e Tecnologia do Sul de Minas Gerais, professor pesquisador. Inconfidentes, Minas Gerais, Brasil. joseluiz.pereira@ifs.ifsuldeminas.edu.br (035) 8425-4036. Praça Tiradentes, 416, centro, Inconfidentes, Minas Gerais, CEP 37.576-000.

3 Instituto Federal de Educação, Ciência e Tecnologia do Sul de Minas Gerais, discente do curso de graduação em Engenharia Agronômica. Inconfidentes, Minas Gerais, Brasil. tamires.teles.souza@hotmail.com Rua JK, 79, Centro, Inconfidentes, Minas Gerais, CEP 37.576-000.
} 
A cercosporiose, cujo agente etiológico é o fungo Cercospora zeae maydis (TEHON; DANIELS, 1925, apud COATES; WHITE, 1994), é atualmente responsável pela descontinuidade de vários híbridos com elevado potencial produtivo, tanto pelos danos causados como pela ampla distribuição no Brasil, sendo encontradas em todas as regiões produtoras (BRITO et al., 2008).

Outra doença foliar de grande importância no Brasil é a mancha branca que, nos últimos anos, tem apresentado elevada severidade, sendo observada em plantas jovens, durante a fase vegetativa, resultando na seca prematura das plantas em genótipos suscetíveis (ROLIM et al., 2007). Sua etiologia ainda é bastante questionada, porém alguns autores, como Paccola-Meirelles et al. (2001), afirmam que é causada pela bactéria Pantoea ananatis. Segundo Fernandes e Oliveira (1997), os híbridos suscetíveis à mancha branca podem chegar a apresentar perdas em torno de $60 \%$ na produção.

Essas perdas, associadas, principalmente, às doenças foliares e à incidência de podridões de grãos, têm causado ampla discussão sobre estratégias de manejo que visem ao desenvolvimento de um programa que permita controlar a doença de forma sustentável, principalmente no que diz respeito ao controle químico e genético (AMARAL, 2005).

Segundo Juliatti et al. (2004), os fungicidas convencionais, à base de triazóis e estrobirulina, registrados para a cultura do milho, apresentam eficiência no controle da cercosporiose, além de promover um efeito fitotônico e, algumas vezes, aumento de produtividade. Porém, nenhum teste nesse sentido foi realizado com fungicidas cujo princípio ativo seja o mancozebe. Já para a mancha branca, os mesmos fungicidas não apresentam eficiência expressiva no controle.

Alguns produtores mais tecnificados estão procurando alternativas para contornar esse problema e possibilitar a utilização de híbridos mais produtivos, embora sejam também suscetíveis a essas doenças. Uma das alternativas é a utilização do fungicida que possui como princípio ativo o mancozebe.

Portanto, os objetivos deste trabalho foram avaliar os efeitos da aplicação de um fungicida, cujo princípio ativo é o mancozebe, na produtividade de híbridos de milho suscetíveis e resistentes à cercosporiose e à mancha branca e verificar a eficiência do produto no controle dessas doenças.

\section{Material e Métodos}

O experimento foi conduzido no município de Inconfidentes, MG, na área experimental do Instituto Federal de Educação, Ciência e Tecnologia do Sul de Minas Gerais. O município está situado a 940 m de altitude, a 22018'47" de latitude sul e 46¹9'54,9" de longitude oeste (FAO, 1985). 0 clima da região é do tipo temperado propriamente dito, ou seja, mesotérmico de inverno seco (Cwb). Apresenta temperatura média anual de $19,3^{\circ} \mathrm{C}$ e precipitação média anual de $1.411 \mathrm{~mm}$ (FAO, 1985). A área possui um latossolo vermelho amarelo eutrófico e está sendo cultivada com milho há várias safras.

Foram utilizados oito híbridos com diferentes características provenientes de empresas sementeiras do Brasil. Os híbridos foram selecionados de acordo com informações das empresas detentoras, relativas ao nível de resistência à cercosporiose e à mancha branca (Tabela 1). 
Tabela 1: Características dos híbridos utilizados para avaliação do efeito do fungicida na produção de grãos.

\begin{tabular}{ccccc}
\hline Cultivar & Base genética & Ciclo & Resistência* & Empresa \\
\hline $2 \mathrm{~B} 587 \mathrm{Hx}$ & $\mathrm{Hs}$ & Precoce & $\mathrm{R}$ & Dow Agrosciences \\
$2 \mathrm{~A} 550 \mathrm{Hx}$ & $\mathrm{Hs}$ & Precoce & $\mathrm{MS}$ & Dow Agrosciences \\
$2 \mathrm{~A} 12 \mathrm{HHx}$ & $\mathrm{HS}$ & Hiper-Precoce & $\mathrm{S}$ & Dow Agrosciences \\
$2 \mathrm{~B} 604 \mathrm{Hx}$ & $\mathrm{Hsm}$ & Precoce & $\mathrm{R}$ & Dow Agrosciences \\
$2 \mathrm{~B} 707 \mathrm{Hx}$ & $\mathrm{Hs}$ & Precoce & $\mathrm{R}$ & Dow Agrosciences \\
Celeron TLTC & $\mathrm{Hs}$ & Precoce & $\mathrm{MR}$ & Syngenta \\
Formula TLTC & $\mathrm{Hs}$ & Hiper-Precoce & $\mathrm{S}$ & Syngenta \\
BM3066 & $\mathrm{Hs}$ & Precoce & $\mathrm{MS}$ & Biomatrix \\
\hline
\end{tabular}

* Resistência à cercosporiose e à mancha branca.

Fonte: Elaboração dos autores.

O experimento foi instalado no início de novembro, época de plantio na região, em solo preparado de maneira convencional. Foi realizada uma aração a $30 \mathrm{~cm}$ de profundidade e, em seguida, duas gradagens para destorroamento e nivelamento.

O delineamento foi feito em blocos casualizados, com três repetições em esquema fatorial, no qual foram avaliados 8 (híbridos) x 3 aplicações do fungicida (sem aplicação, 1 aplicação no estádio V6 e 2 aplicações V6 + pré-pendoamento). As parcelas foram constituídas de quatro fileiras de 5,0 $\mathrm{m}$ de comprimento, sendo as duas fileiras centrais consideradas como úteis. 0 espaçamento entre fileiras foi de $0,80 \mathrm{~m}$ e a densidade de 5 plantas por metro linear, atingindo o estande final de 62.500 plantas ha-1 após o desbaste.

Na semeadura, foram utilizados $450 \mathrm{~kg} \mathrm{ha}^{-1}$ da fórmula 08:28:16. Em cobertura, foram aplicados $350 \mathrm{~kg} \mathrm{ha}^{-1}$ da fórmula 30:00:10, no estádio de 5-6 folhas totalmente expandidas.

Para o controle de plantas invasoras, prevenção de pragas e uma melhor nutrição das plantas, foi feita uma aplicação de herbicida, cujo princípio ativo é tembotriona, na dose de $200 \mathrm{ml} \mathrm{ha}^{-1}$, uma aplicação do inseticida Decis 25 EC, na dose de $100 \mathrm{ml} \mathrm{ha}^{-1}$, e do adubo foliar Superon, na dose de $1 \mathrm{~kg} \mathrm{ha}^{-1}$.

O controle químico da doença foi realizado com um fungicida, cujo princípio ativo é o mancozebe. A dosagem utilizada do produto comercial foi de $2 \mathrm{~kg} \mathrm{ha}^{-1}$ em cada aplicação, determinada com base na recomendação.

O início do progresso da doença ocorreu por infecção natural. Foram realizadas sete avaliações da severidade da doença cercosporiose e da mancha branca, com o auxílio da escala proposta pela Agroceres (1996), a intervalos de sete dias, a partir dos 90 dias após a emergência, visualmente, por meio de escala de notas variando de 1 (altamente resistente) a 9 (altamente susceptível), de acordo com a \% de área foliar.

Foram avaliados os caracteres altura de planta e espiga ( $A P$ e $A E$ ), em centímetros, e a área abaixo da curva de progresso da doença (AACPD), proposta por Shaner e Finney (1977). A produtividade de grãos por parcela foi transformada para hectare e ajustada para $13 \%$ de umidade.

Os dados foram submetidos à análise de variância, utilizando-se o Software SISVAR (FERREI$R A, 2000)$. As médias entre os tratamentos foram agrupadas pelo teste de Scott-Knott $(P<0,05)$.

\section{Resultados e Discussão}

Todas as variáveis analisadas foram influenciadas significativamente $(P \leq 0,01)$ pelo fator híbrido, o que pode ser justificado pelas diferenças de bases genéticas dos híbridos utilizados neste 
experimento. Os dados corroboram os resultados de trabalhos da literatura nos quais também foram encontradas diferenças significativas para as mesmas variáveis analisadas (PENARIOL et al., 2003; CARDOSO et al., 2003) (Tabela 2).

A aplicação do fungicida teve influência significativa na AACPD de ambas as doenças $(P \leq 0,01)$.

Tabela 2: Resumo da análise de variância para a área abaixo da curva de progresso da doença mancha branca (AACPD MB), para a área abaixo da curva de progresso da doença cercosporiose (AACPD $C$ ), para altura de plantas (AP), altura de espigas (AE) e para produtividade de grãos (PG), na cidade de Inconfidentes-MG, no ano agrícola de 2011/2012.

\begin{tabular}{cccccc}
\hline Fontes de variação & AACPD MB & AACPD C & AP & AE & PG \\
\hline Fungicidas & $10844,2^{* *}$ & $8740,5^{* *}$ & $0,028^{\text {ns }}$ & $0,009^{\text {ns }}$ & $358659,2^{\text {ns }}$ \\
Híbridos & $34515,9^{* *}$ & $30095,5^{* *}$ & $0,150^{* *}$ & $0,101^{\text {}}$ & $6954260,6^{* *}$ \\
Fung*Híbridos & $1236,4^{* *}$ & $382,5^{\text {ns }}$ & $0,01^{\text {ns }}$ & $0,101^{\text {ns }}$ & $949272,9^{\text {ns }}$ \\
C.V.(\%) & 12,1 & 11,0 & $\mathbf{4 , 5}$ & $\mathbf{9 , 1}$ & $\mathbf{9 , 0}$ \\
\hline
\end{tabular}

ns Não Significativo, ${ }^{* *}$ Significativo a $1 \%$ de probabilidade.

Os híbridos 2B587HX e 2B604HX obtiveram menor severidade da doença mancha-branca com e sem aplicação do fungicida, o que corrobora os dados da Tabela 1, de acordo com as informações de resistência à doença. O tratamento com duas aplicações (V6 + Pré-pendoamento) do fungicida proporcionou maior controle da doença para todos os híbridos (Tabela 3).

Resultados semelhantes foram encontrados por Pinto (2004), os quais mostraram que os fungicidas à base de mancozebe e azoxystrobin foram eficientes para o controle da mancha branca. Para Jardiner et al., (2009), o mancozebe também foi eficiente no controle da mancha branca quando combinado com outros princípios ativos.

Tabela 3: Resultados médios da área abaixo da curva de progresso da doença (AACPD) da Mancha Branca para oito híbridos de milho com e sem a aplicação do fungicida, na cidade de Inconfidentes-MG, no ano agrícola de $2011 / 2012$.

\begin{tabular}{cccc}
\hline \multirow{2}{*}{ Híbridos } & \multicolumn{3}{c}{ Fungicida } \\
\cline { 2 - 4 } & Sem Aplicação & 1 Aplicação V6 & 2 Aplicações V6+Pre P. \\
\hline 2A120Hx & 293,1 c D & 245,8 b E & 196,6 a C \\
2A550Hx & 188,1 c B & 144,8 b C & 111,8 a B \\
2B587Hx & 92,6 a A & 107,5 a B & 82,5 a A \\
2B604Hx & 81,1 a A & 68,3 a A & 68,3 a A \\
2B707Hx & 105,6 b A & 104,3 b B & 72,6 a A \\
BM3066 & 105,6 a A & 107,1 a B & 117,3 a B \\
CeleronTLTC & 220,3 b C & 187,8 a D & 177,5 a C \\
FórmulaTLTC & 237,0 c C & 195,3 b D & 158,1 a C \\
\hline
\end{tabular}

Médias seguidas de letras distintas minúsculas na linha diferem entre si pelo teste de Scott-Knott $(P \leq 0,05)$. Médias seguidas de letras distintas maiúsculas na coluna diferem entre si pelo teste de Scott-Knott $(P \leq 0,05)$.

Para a doença Cercospora, o tratamento com duas aplicações (V6 + Pré-pendoamento) também proporcionou menor área abaixo da curva de progresso da doença (AACPD) para todos os híbridos com relação aos demais tratamentos (Tabela 4). 
Tabela 4: Resultados médios da área abaixo da curva de progresso da doença (AACPD) da cercosporiose para oito híbridos de milho com e sem a aplicação do fungicida, na cidade de Inconfidentes-MG, no ano agrícola de $2011 / 2012$.

\begin{tabular}{cccc}
\hline \multirow{2}{*}{ Híbridos } & \multicolumn{3}{c}{ Fungicida } \\
\cline { 2 - 4 } & Sem Aplicação & 1 Aplicação V6 & 2 Aplicações V6 + Pre P. \\
\hline 2A120Hx & 231,3 b C & 230,6 b C & 170,5 a C \\
2A550Hx & 112,0 a A & 114,8 a A & 95,8 a B \\
2B587Hx & 99,5 b A & 116,5 b A & 79,1 a A \\
2B604Hx & 99,5 b A & 99,5 b A & 60,8 a A \\
2B707Hx & 116,5 b A & 99,5 b A & 67,6 a A \\
BM3066 & 116,0 a A & 95,3 a A & 94,5 a B \\
CeleronTLTC & 200,3 a B & 189,6 a B & 172,6 a C \\
FórmulaTLTC & 236,8 b C & 240,3 b C & 193,6 a C \\
\hline
\end{tabular}

Médias seguidas de letras distintas minúsculas na linha diferem entre si pelo teste de Scott-Knott $(P<0,05)$. Médias seguidas de letras distintas maiúsculas na coluna diferem entre si pelo teste de Scott-Knott $(P<0,05)$.

A média geral do experimento foi de $12.824 \mathrm{~kg} \cdot \mathrm{ha}^{-1}$. Essa produtividade é considerada ótima para a região e superior à encontrada por Brito et al.(2008).

O híbrido 2A120HX foi o que obteve a menor produtividade de grãos, $11.102 \mathrm{~kg}^{\text {. ha-1 }}$, fato que pode ter ocorrido pelo motivo de os híbridos $2 \mathrm{~A}$ serem mais recomendados para altitudes mais baixas. Os demais híbridos utilizados não diferiram estatisticamente entre si, e o híbrido que obteve a maior produtividade de grãos foi o Fórmula TLTC com 14.092 kg.ha-1 (Tabela 5).

Tabela 5: Produtividade média de grãos de oito híbridos de milho sem a aplicação fungicida, com 1 aplicação no estádio V6 e com 2 aplicações (V6+ Pré-Pendoamento), na cidade de Inconfidentes-MG, no ano agrícola de $2011 / 2012$.

\begin{tabular}{ccccc}
\hline \multirow{2}{*}{ Híbridos } & \multicolumn{5}{c}{ Fungicida } \\
\cline { 2 - 5 } & Sem Aplicação & 1 Aplicação V6 & 2 Aplicações V6+Pre P. & Média \\
\hline 2A120 Hx & 10.983 & 11.308 & 11.015 & $11.102 \mathrm{~B}$ \\
2A550Hx & 12.669 & 12.945 & 12.937 & $12.850 \mathrm{~A}$ \\
2B587Hx & 13.473 & 13.884 & 12.273 & $13.210 \mathrm{~A}$ \\
2B604Hx & 13.013 & 12.968 & 12.488 & $12.823 \mathrm{~A}$ \\
2B707Hx & 12.524 & 13.567 & 14.339 & $13.477 \mathrm{~A}$ \\
BM3066 & 11.906 & 12.749 & 12.320 & $12.325 \mathrm{~A}$ \\
Celeron TLTC & 13.067 & 12.215 & 12.857 & $12.713 \mathrm{~A}$ \\
Fórmula TLTC & 14.647 & 14.050 & 13.577 & $14.092 \mathrm{~A}$ \\
Média & $\mathbf{1 2 . 7 8 5 ~ A}$ & $\mathbf{1 2 . 9 6 1 ~ A}$ & $\mathbf{1 2 . 7 2 6 ~ A}$ & $\mathbf{1 2 . 8 2 4}$ \\
\hline
\end{tabular}

Médias seguidas de letras distintas maiúsculas na linha ou coluna diferem entre si pelo teste de Scott-Knott $(P \leq 0,05)$.

A severidade das doenças neste experimento foi menor do que a encontrada no experimento de Brito (2008), cujo resultado mostrou que a aplicação do fungicida Dithane NT diminuiu a severidade das doenças mancha branca e cercosporiose.

Esse mesmo autor encontrou redução significativa na produtividade de grãos em decorrência da alta severidade da doença nas folhas, diminuindo a área fotossintetizante. Os danos também ocorreram pelo enfraquecimento da planta, o que, por sua vez, favorece podridões de colmo, levando-a ao tombamento. No Brasil, dados acerca dos danos causados pelo patógeno são incipientes, porém, teme-se que eles possam atingir patamares idênticos aos alcançados em outros países. Os danos, 
no entanto, não se restringem somente à redução causada diretamente pelo patógeno. Na safra de 2000 e 2001, vários híbridos altamente produtivos tiveram que ser substituídos por outros de menor rendimento, mas com boa resistência.

\section{Conclusões}

A aplicação do fungicida que possui como princípio ativo o mancozebe foi eficiente no controle das doenças mancha branca e cercosporiose; entretanto, não proporcionou aumento na produtividade de grãos dos híbridos utilizados neste experimento.

A aplicação do fungicida no estádio V6 mais uma aplicação no estádio de pré-pendoamento das plantas de milho diminuiu a severidade da doença cercosporiose.

\section{Evaluation of corn yield and control of leaf spot diseases}

\section{Abstract}

Currently there are dozens of foliar diseases that have caused significant losses in corn. Among them stand out from the gray leaf spot and white spot. This study was therefore to evaluate the effect of applying a fungicide, which has as active ingredient mancozeb, productivity of maize hybrids, and check its efficiency in controlling foliar diseases Cercospora leaf spot and white spot. The experiment was conducted in the agricultural year 2011/2012, in the experimental farm of IFSULDEMINAS Campus Inconfidentes. To conduct the study were selected hybrids used in accordance with the levels of resistance to disease. The design was done in randomized block design with three replications in

a factorial design, which evaluated 8 (hybrid) $\times 3$ fungicide applications. Seven visual assessments of disease severity were held from the 90 days after emergence, through grade scale ranging from 1 (highly resistant) to 9 (highly susceptible). The grains were collected to obtain the yield of hybrids, and moisture was adjusted to $13 \%$. The application of fungicide was effective in controlling the diseases white spot and Cercospora leaf spot, however, did not increase grain yield of hybrids used in this experiment. The application of fungicide in V6 and pre-bolting of corn plants was more efficient.

Keywords: Cercospora zeae maydis. Phaeosphaeria maydis. Mancozeb. Severity.

\section{Referências}

AGROCERES. Guia Agroceres de sanidade. São Paulo: Sementes Agroceres, 1996. 72 p.

AMARAL, A. L. do; DAL SOGLIO, F. K.; CARLI, M. L. de; BARBOSA NETO, J. F. Pathogenic fungi causing symptons similar to Phaeosphaeria leaf spot maize in Brazil. Plant Disease, 2005.

BRITO, A. H.; PINHO, R. G. von; SOUZA FILHO, A. X.; ALTOÉ, T. F. Avaliação da severidade da Cercosporiose e rendimento de grãos em híbridos comerciais de milho. Revista Brasileira de Milho e Sorgo, Sete Lagoas, v.7, n.1, p.19-31, 2008.

CARDOSO, M. J.; CARVALHO, H. W. L.; SANTOS, M. X.; LEAL, M. L. S.; OLIVEIRA, A. C. Desempenho de híbridos de milho na região meio-norte do brasil. Revista Brasileira de Milho e Sorgo, v.2, n.1, p.43-52, 2003. 
COATES, S. T.; WHITE, D. G. Sources of resistance to gray leaf spot of corn. Plant Disease, São Paulo, v.78, n.11, p.1153-1155, nov. 1994.

FAO. Agroclimatological data for Latin América and Caribean. Roma, 1985. (Coleção FAO: Produção e Proteção Vegetal, v. 24).

FERNANDES, F. T.; OLIVEIRA, E. Principais doenças da cultura do milho. Sete Lagoas: Embrapa/ CNPMS, 1997. 80p. (Circular Técnica, 26).

FERREIRA, D. F. SISVAR: sistema de análise de variância, Versão 3.04, Lavras/DEX, 2000.

GUARESCHI, R. F. GAZOLlA, P. R. PERIN, A. ROCHA, A. C. Produção de massa de milho silagem em função do arranjo populacional e adubação. Revista Ciência Agronômica, v.39, n.3, p.468-475, 2008.

JARDINE, D. F.; LACA-BUENDÍA, J. P. Eficiência de fungicidas no controle de doenças foliares na cultura do milho. FAZU em Revista, Uberaba, n.6, p.11-52, 2009.

JULIATTI, F.C.; APPELT, C. C. N. S.; BRITO, C. H.; GOMES, L. S.; BRANDÃO, A. M.; HAMAWAKI, O. T.; MELO, B. Controle da feosféria, ferrugem comum e cercosporiose pelo uso da resistência genética, fungicidas e épocas de aplicação na cultura do milho. Bioscience Journal, n.20, p.45-54, 2004.

PACCOLA-MEIRELLES, L. D.; FERREIRA, A. S.; MEIRELLES, W. F.; MARRIEL, I. E.; CASELA, C. R. Detection of a bacterium associated with a leaf spot disease of maize in Brazil. Journal of Phytopathology, Berlin, v.149, n.5, p.275-279, maio/ 2001.

PENARIOL, F. G.; FORNASIERI FILHO, D.; COICEV, L.; BORDIN, L.; FARINELLI, R. Comportamento de cultivares de milho semeados em diferentes espaçamentos entre linhas e densidades populacionais, na safrinha. Revista Brasileira de Milho e Sorgo, v.2, p.52-60, 2003.

PINTO, N. F. J. de A. Controle químico de doenças foliares em milho. Revista Brasileira de Milho e Sorgo, v.3, n.1, p.134-138, 2004.

POZAR, G.; BUTRUILLE, D.; DINIZ, H. S.; VIGLIONI, J. P. Mapping and validation of quantitative trait loci for resistance to cercospora infection in tropical maize (Zea mays L.). Theoretical and Applied Genetics, Berlin, v.118, n.3, p.553-564, fev. 2009.

ROLIM, G. de S. JÚNIOR, M. J. P. FANTIN, G. M. BRUNINI, O. DUARTE, A. P. DUDIENAS, C. Modelo agrometeorológico regional para a estimativa da severidade da mancha de Phaeosphaeria em milho safrinha no estado de São Paulo, Brasil. Bragantia, Campinas, v.66, n.4, p.721-728, dez.2007.

SHANER, G.; Finney, R. E. The effect of nitrogen fertilization on the expression of slowmildewing resistance in Knox wheat. Phytopathology, 1977.

TRENTO, S. M.; IRGANG, H. H.; REIS, E. M. Efeito da rotação de culturas, da monocultura e da densidade de plantas na incidência de grãos ardidos em milho. Fitopatologia Brasileira, v.27, n.6, p.609-613, 2002.

\section{Histórico editorial}

Submetido em: 10/03/2014

Aceito em: 30/10/2014 